\title{
Teleodontologia no processo de divulgação e implementação de Bancos de Dentes Humanos
}

\author{
Mary Caroline Skelton-Macedo*, Sérgio Brossi Botta**, José Carlos Peorossilmparato***, \\ João Humberto Antoniazzi****, Ana Estela Haddad***** \\ * Professora Doutora de Teleodontologia, Pesquisadora do Núcleo de Teleodon- \\ tologia; Universidade de São Paulo. \\ ** Professor Doutorde Dentística da Universidade Nove de Julho, Coordenador \\ Banco de Dentes Humanos Universidade Nove de Julho \\ *** Professor Doutor em Odontopediatria na Faculdade de Odontologia da Uni- \\ versidade de São Paulo, Coordenador Banco de Dentes Faculdade de Odonto- \\ logia da Universidade de São Paulo \\ **** Professor Titular de Endodontia e Coordenador do Núcleo de Teleodontologia \\ da Faculdade de Odontologia da Universidade de São Paulo \\ ***** Professora Adjunta - Odontopediatria - Faculdade de Odontologia da Univer- \\ sidade de São Paulo, Coordenadora do Programa Nacional de Telessaúde do \\ Ministério da Saúde (2006-2012)
}

\section{RESUMO}

$\mathrm{Na}$ era da colaboração, surge o Ensino a Distância $(\mathrm{EaD})$ como poderosa ferramenta de divulgação de realidades, permitindo que a importância do BDH seja divulgada adequadamente. Diversas iniciativas estão sendotomadas de modo articulado, a fim de facilitar a criação e a consolidação de uma rede de colaborativa detrabalho em Telessaúde e Teleodontologia para a divulgação e implementação de Bancos de Dentes Humanosem sua faculdade ou centro de pesquisasbaseado no caminho trilhado pela Faculdade de Odontologia da USP.

Descritores: Telessaúde, Teleodontologia, Ensino a Distância, Redes Sociais, Banco de Dentes.

\section{INTRODUÇÃO}

A Teleodontologia, como campo de conhecimento integrante da Telessaúde,vem evoluindo nos anos recentes, em especial com ênfase na teleducação interativa, na teleassistência e na produção de pesquisas multicêntricas.

Inegável é a importância do Banco de Dentes Humanos (BDH) e seu papel relevante na condução de trabalhos e reflexões científicas que alteraram a condução da atividade restauradora dos sorrisos. Somado a isso, a grande contribuição dos estudos de caráter ético-legal puderam permitir a construção de rumos seguros para a manutenção dos $\mathrm{BDH}$, propiciando condições de pesquisa segura e apropriada.

Cabe no momento observar a contribuição que a educação pode promover nesse contexto, permitindo gerar conhecimento que não somente explica razões e importância, mas ensina a construir um BDH com a possibilidade de colaborar com novas reflexões científicas.

Divulgada a idéia do $\mathrm{BDH}$, muitos foram os pesquisadores que se interessaram em construir seus próprios bancos, em diferentes estados de um país continental como 
o Brasil. Legalmente inviabilizou-se o uso de peças anatômicas colhidas aleatoriamente e, além de existirem coleções pessoais que necessitavam aporte para a legalidade, preocupava a necessidade de se obter peças para o treinamento nos cursos de graduação e pós-graduação. Há que se refletir também sobre a melhoria sócio-econômico-cultural da população, o que deve diminuir significativa e progressivamente a disponibilidade de dentes para treinamento e/ou pesquisa.

Todo o cenário descrito acontece no momento em que a comunicação humana passa pela assimilação de maneiras inovadoras de se divulgar informações e proporciona ferramentas poderosas no sentido de amplificar um sinal que deve ser recebido por toda uma comunidade: a necessidade de se observar as questões relativas às peças anatômicas que, no passado, eram esquecidas debaixo de um travesseiro, no caso de dentes decíduos, ou eram guardadas em coleções pessoais como lembrança ou base de pesquisas solitárias.

\section{O FUTURO DA APLICAÇÃO DE DENTES HUMANOS E A TELEO- DONTOLOGIA}

Refletir sobre o futuro implica em observar as condições que contextualizam a atualidade e projetar mudanças para uma realidade que tem se tornado cada vez mais próxima. As inovações tecnológicas têm acontecido muito rapidamente e sua introdução no cotidiano tem desafiado os mais atualizados formadores de opinião.

No caso do BDH, faz-se necessário observar a utilização dos espécimes nos campos do ensino e da pesquisa. Muitos espécimes têm sido empregados para que alunos possam ter contato com o seu futuro campo de trabalho, e isso significa alimentar cada um dos mais de 200 cursos de graduação de Odontologia do país. Conside- rando a variação do numero de alunos por curso, tomando-se uma media de 50 por curso, isso implica em disponibilizar-se de aproximadamente 10.000 espécimes de cada um dos grupamentos dentais para atender somente a essa demanda educacional.

Se existem ferramentas educacionais que podem substituir o emprego desses espécimes, então estamos atrasados em estudá-las e torná-las significativas ao aprendizado humano na área de Ciências da Saúde. Hoje já é possível disponibilizar por CD, DVD, web ou TV Digital Interativa: vídeos, apostilas, descritivos em áudio, tutoriais dos mais diversos para as diferentes especialidades odontológicas, animações, construções em 3D, exercícios, objetos de aprendizagem integrados e mais uma infinidade de associações de material educacional. Uma boa condução do processo de ensino-aprendizagem dá o toque final ao aprendizado significativo e possibilita a construção do raciocínio, levando em consideração a abstração necessária à idealização mental que compreende o entendimento dos conceitos de anatomia e a habilidade em torná-los aptos para o desenvolvimento da atividade prática, acorde a especialidade estudada. A Teleodontologia tem muito a colaborar nos aspectos observados.

Caberia ao $\mathrm{BDH}$ refletir e trabalhar na confecção, testes e fidelidade de dentes artificiais para o ensino, treinamento, etc., utilizando materiais adequados e tecnologias digitais sofisticadas para a perfeita simulação do real, quer do espécime (dente) quer dos recursos de tratamento (equipamentos, instrumental e material) todos digitais - em realidade virtual. Muitos têm sido os avanços nesta área, porém com pouca significância para as Ciências da Saúde. Não se pode continuar a defender o fato de que o $\mathrm{EaD}$ não cabe para as atividades humanas 
que exigem práticas nos seres humanos: repete-se aqui o fato de que são necessários estudos que viabilizem as potencialidades e reflitam sobre as limitações, impondo qualificações distintas aos processos.

Por outro lado, na pesquisa exige-se a utilização dos espécimes para que se possa tornar os resultados de análise significativos do ponto de vista do ensaio experimental. Neste aspecto, a Teleodontologia poderia oferecer ferramentas de apoio à troca de informações entre bancos, no que diz respeito ao controle de estoques e também no compartilhamento de conhecimentos quanto à disponibilidade e manutenção dos espécimes.

\section{TIPOS DE COMUNICAÇÃO ELE- TRÔNICA}

A comunicação por meio eletrônico sofre críticas que não conseguem se estabelecer quanto ao objetivo a que se destinam, já que têm provado eficácia a cada novo momento.

Há uma comunicação que se pode chamar assíncrona, em que os atores estão conectados em momentos distintos, mas podem se comunicar pela troca de mensagens eletrônicas, que serão lidas e respondidas assim que o destinatário se conectar e coletá-las. Tais mensagens permitem uma troca usual de correio eletrônico, mas podem se inserir no contexto de um fórum, aberto ou fechado, considerando-se aqui o potencial de reflexão para a construção da resposta. Pedagogicamente, esta reflexão permite a reconstrução da informação e, portanto, tem um papel significativo na apreensão de um novo conhecimento.

Existe também a possibilidade de uma comunicação síncrona, em que os atores encontram-se conectados ao mesmo tempo, podendo comunicar-se por mensagens instantâneas, áudio conferencia, tele- conferência, web conferência ou videoconferência de ponto-a-ponto ou multiponto. Essa maneira de se comunicar releva o pensamento em brainstorm (tempestade de idéias), com construções diretas, com reflexão muitas vezes posterior ao evento em si.

Uma áudio-conferência pode ser realizada por telefone ou por meio de ferramentas de comunicação eletrônica (ex: Skype $\left.^{\circledR 1}\right)$ : os atores não se veem, mas podem ouvir aos demais e participar de uma conversa em que todos se ouvem e podem falar. Em geral uma conexão de baixa velocidade permite uma qualidade razoável para a troca desses dados (ex: 512kbps - o mesmo limite que tem sido estendido no Plano Nacional de Banda Larga e interiorização da internet no Brasil ${ }^{2}$ ).

A teleconferência tem um protocolo de troca de dados diferente, com qualidade de imagem semelhante à da televisão e com a interatividade entre os atores realizada por outro meio de comunicação (telefone, email, mensagens instantâneas, salas de batepapo, etc.).

$\mathrm{Na}$ web conferência existe a necessidade da utilização de um aplicativo que utilize o protocolo web para realizar a troca de dados: os atores têm webcâmeras em seus computadores e o limite de participantes é determinado pela capacidade que o aplicativo permite. O aplicativo Skype ${ }^{\circledR 1}$ permite web conferência de dois atores e, a partir de um terceiro, passa automaticamente a sincronizar uma áudio-conferência, garantindo que os atores se comuniquem, porém sem o vídeo. Aplicativos como o Elluminate $^{\circledR 3}$ ou Adobe Connect ${ }^{\circledR 4}$ permitem mais atores em um mesmo ambiente virtual, com áudio e imagem, na dependência da banda que estejam se conectando para garantir a permanência da imagem: sempre que o sistema perceber a baixa velocidade na troca de dados, optará pelo en- 
vio do áudio, em detrimento do vídeo, a fim de garantir a comunicabilidade.

Já a videoconferência (VC) garante a melhor qualidade de som/imagem por utilizar o protocolo internet para troca de dados, mas exigindo equipamento apropriado nas pontas conectadas (ex: Polycom ${ }^{\circledR 5}$, Tandberg ${ }^{\circledR 6}$ ). O equipamento de $\mathrm{VC}$ tem um custo alto, que vem sendo reduzido na medida em que se assimilam suas aplicações no dia-a-dia das diversas áreas do conhecimento.

Todos esses tipos de comunicação síncrona podem ser aplicados ponto-a-ponto (em que existem somente dois lugares físicos conectados, mas que, na dependência do ambiente físico, podem conter mais pessoas para uso de uma mesma câmera) ou multiponto (no qual existem inúmeros lugares conectados, nos quais pode haver desde uma a muitas pessoas, multiplicando a comunicação por projeção multimídia para os participantes da atividade).

As inúmeras formas de comunicação possibilitam diversas maneiras de se construir e compartilhar conhecimentos. Lembrando Demo ${ }^{7}$ em Questões para a Teleducação (1999): “A instrução eletrônica não é, de si, educativa ou formativa. É facilmente informativa, atraente e dinâmica, mas seu impacto educativo provém da ambiência humana implicada no processo formativo, e não dela mesma". Isso significa que os professores, tutores ou facilitadores do processo têm que conhecer suas gamas, aplicações e possíveis limites para tornar o meio de comunicação um facilitador na troca da informação significativa do ponto de vista pedagógico e assim dignificar seu uso no contexto educacional.

\section{AMBIENTES VIRTUAIS DE APRENDIZAGEM}

Quando se compreendeu a potencialidade da rede mundial de computadores em comunicar pessoas, muitas foram as aplicações destinadas a agrupar pessoas com diferentes interesses. No âmbito pedagógico foram desenvolvidos sistemas que capazes de gerenciar/mediar as atividades de forma a reproduzir o ambiente de sala de aula e contexto de escola/faculdade. São os LMS - Learning Management Systems - ou AVA - Ambientes Virtuais de Aprendizagem que permitem apoio pedagógico ao ensino presencial ou gerenciam o processo de ensino-aprendizagem totalmente telepresencial, ou seja, onde professores e estudantes se encontram em distintas situações geográficas. O termo Educação a Distânciaé discutido por muitos estudiosos, pois induz ao pensamento de que o processo acontece no distanciamento dos atores, o que não é realidade nos cursos de sucesso registrados na literatura. Observou-se ao longo das aplicações de cursos chamados a distância que a evasão de estudantes ocorreu justamente por se sentirem abandonados em meio ao aprendizado $^{8}$.

Há inúmeros AVA na atualidade, destacando-se o WebCT ${ }^{\circledR 9}$ (software pago), um dos primeiros a ser utilizado nos EUA no meio corporativo, porém com severas críticas para aplicação no âmbito acadêmico. Um dos seus autores, o Prof. Martin Dougiamas, apropriando-se das criticas realizadas ao WebCT, desenvolveu o Moodle ${ }^{\circledR 10}$ (freeware de código aberto), hoje de maior utilização mundial. Outros exemplos de AVA são o $\mathrm{CoL}^{\circledR 11}$ (USP); TelEduc ${ }^{\circledR 12}$ (UNICAMP); $\operatorname{dotLRN}^{\circledR 13}$; Blackboard $^{\circledR 14}$; eProInfo ${ }^{\circledR 15}$; Dokeos ${ }^{\circledR 16}$ dentre outros. 
Segundo a Profa. Vani Kenski ${ }^{17}$, No ciberespaço, essa união de cidadãos conectados, agrupados virtualmente em torno de interesses especificos, pode construir uma comunidade a partir do momento em que se estabelecem regras, valores, limites, usos e costumes, a netiqueta ${ }^{18}$, com as restrições e os sentimentos de acolhimento e 'pertencimento' ao grupo.

$\mathrm{Na}$ Europa existe um crescimento acentuado de um movimento de certificação de competências, no qual profissionais podem transformar o conhecimento adquirido em pontos, como os obtidos em cursos formais (Telles, 2010) ${ }^{19}$. Um protocolo foi aprovado no âmbito da Comunidade Européia para padronizar o aspecto conceitual e o protocolar (incluindo a explicitação de objetivos de aprendizagem em termos de competências).

Com esse conhecimento, é possível desenvolver cursos formais, baseados em competências e realizados em AVA, com tutoria ativa e qualificação de profissionais, técnicos e estudantes quanto a Banco de Dentes Humanos, sua importância e quais os passos para a sua criação. Outra possibilidade interessante é a criação de uma Rede Social que congregue os interessados e permita a troca de informações que possa qualificar continuamente os bancos criados.

\section{DENTES ARTIFICIAIS E SIMULA- DORES EM ODONTOLOGIA}

As alternativas viáveis para a escassez de dentes humanos para treinamento laboratorial fez com que os estudos avaliassem a possibilidade de uso de dentes feitos em resina das mais variadas formas de cura. Para algumas áreas da Odontologia, esses dentes se aplicariam sem grandes problemas relacionados às exigências da ação do profissional sobre o elemento dental (ex:
Periodontia), porém para outras áreas do conhecimento, os artificiais não conseguem reproduzir elementos importantes da anatomia interna, comprometendo sua utilização como facilitador do aprendizado (ex: Endodontia). Quanto aos aspectos radiográficos e até de aproximação de dureza, esses elementos foram relativamente bem desenvolvidos, mas ainda faltam estudos e testes para que possam ser utilizados por todas as especialidades.

$\mathrm{Na}$ evolução dos sistemas eletrônicos, percebeu-se que softwares de desenho (ex: Photoshop ${ }^{\circledR 20}$ ), somados ao uso de periféricos específicos (mesa digitalizadora com caneta), podem ser mais bem desenvolvidos no sentido de permitir ao desenhista ampliar os aspectos relativos à pressão que determina sobre a caneta, fazendo com que sepossa determinar diversas espessuras de traço e melhoria do resultado final. Isso remete aos diversos torques que precisam ser treinados na utilização da caneta de alta rotação ou de um ultrassom. Ademais, há que se considerar os avanços no sentido de desenvolver simuladores: em breve haverá novidades interessantes, pois vários centros de estudo têm se disposto a desenvolver simuladores que integram funções específicas para as áreas de treinamento diversas.

Em março de 2010 foi divulgado um robô japonês ${ }^{21}$ que responde a procedimentos odontológicos com dor: os simuladores têm sido desenvolvidos rapidamente e em breve será possível evidenciar sua aplicação prática, com evolução continua de suas potencialidades, contrapondo de forma significativa e estendida a necessidade de peças anatômicas para treinamento.

De qualquer maneira, sobre as possibilidades de rompimento da condição presencial física e síncronano processo de ensino-aprendizagem, seja para a construção de um banco de dentes humanos seja para a 
formação de outras competências, é necessário refletir sobre o papel do professor na era da comunicação colaborativa, significativa e sem limites. Percebe-se que os alunos/estudantes são mais afeitos às novas tecnologias e as utilizam com facilidade no dia-a-dia, inclusive para estudos e registros de trabalhos, relatórios e etc., com grandes mudanças nos cenários da troca de informações entre pares. Observe-se aqui o que foi apresentado recentemente no filme Avatar $^{\circledR}$ (Diretor: James Cameron, 2009), em que um pesquisador no ano de 2154 faz os registros de sua pesquisa em arquivos de $v i$ deolog.

Recentemente alguns autores consideraram o fato de que o abismo entre gerações já não ocorre entre duas ou três, mas está ocorrendo numa mesma geração por causa da multiplicação do conhecimento científico e inovações tecnológicas, caso do Prof. Silvio Meira ${ }^{22}$ : “(...) A dinâmica do conhecimento hoje é completamente diferente, com as pessoas aprendendo por fora do sistema e com a depreciação do conhecimento muito mais acelerada do que em qualquer periodo da história, o principal papel da escola passa a ser o de preparar as pessoas para três coisas: aprender, desaprender e reaprender (...)".

Em artigo do New York Timeso articulista Tom Brady ${ }^{23}$ observa que o abismo de conhecimento atualizado já tem atingido irmãos - o mais velho para com o mais novo - e tem a tendência de se ampliar mesmo considerando idades aproximadas. Para isso é necessário que se reveja o papel do professor/tutor e se reconsidere a necessidade de compreensão de que o corpo docente ainda se utiliza de métodos que não incluem as inovações da comunicação e nem tem considerado o potencial destas nas mudanças das relações sociais e, portanto, alteran- do significativamente o papel do educador junto ao seu corpo discente.

Como afirma Pierre Levy (1999) ${ }^{24}$, trabalhar hoje equivale cada vez maisa aprender a transmitir saberes e produzir conhecimentos. (...) o ciberespaço suporta tecnologias intelectuais que ampliam, exteriorizam e alteram muitas funções cognitivas humanas.

Baseando-se no exposto anteriormente, podemos afirmar que urge a necessidade de se repensar o papel do educador frente às novas tecnologias.

As iniciativas da Rede Nacional de Teleodontologia tem por objetivo estabelecer um espaço para a troca de experiências,compartilhamento de expertises e envolvimento dosNúcleos de Teleodontologia de cada estado em parcerias ${ }^{25}$.

\section{CONSIDERAÇÕES FINAIS}

Diante do aumento da demanda por elementos dentais em pesquisas e a escassez de trabalhos que comprovem a total substituição dos elementos dentais naturais nos treinamentos dos cursos de graduação em Odontologia, os Bancos de Dentes Humanos tornam-se instituições de fundamental importância para suprir esta demanda, assim como tem um importante papel educador na conscientização quanto à substituição destes elementos por novas possibilidades tecnológicas, considerando a real necessidade de redução na utilização dos dentes naturais.

Como se pode observar anteriormente, inúmeras são as alternativas de expansão dos conhecimentos adquiridos pelos BDHs, e o uso das ferramentas educacionais providas pelo ambiente da Teleodontologia tornará este conhecimento mais próximo, a partir do momento em que será possível a intercomunicação rápida e eficiente entre todos os BDHs brasileiros mes- 
mo em grandes distâncias, assim como permitirá a divulgação de tecnologias que minimizem o uso de dentes naturais e a qualificação dos profissionais que interagem com os BDHs. Desta forma, a Teleodontologia tem se mostrado como uma forma promissora para o bom funcionamento de um Banco de Dentes Humanos, sendo este relacionamento vital para o sucesso de ambas as instituições.

\section{REFERÊNCIAS}

1. Skype - disponível em www.skype.com/intl/pt, acesso em janeiro de 2013.

2. PNBL - disponível em www.mc.gov.br/plano-nacional-parabanda-larga, acesso em janeiro de 2013.

3. Elluminate $^{\circledR} \quad-$ disponível em www.elluminate.com, acesso em janeiro de 2013.

4. Adobe Connet $^{\circledR}-$ disponível em www.adobe.com $/ \mathrm{br} /$ products/connect, acesso em agosto de 2010.

5. Polycom - disponível em www.polycom.com, acesso em janeiro de 2013

6. Tandberg - disponível em WWW.tandberg.com, acesso em janeiro de 2013

7. Demo P. Questões para a Teleducação, $3^{\mathrm{a}}$ ed., Ed: Vozes, 1998.

8. Santos EM, Tomotake ME, Neto JDO, Cazarini EW, Araújo EM, Oliveira, SRM. Evasão na Educação a Distância: identificando causas e propondo estratégias de prevenção. Publicado em maio de 2008, disponível em www.abed.org.br/congresso2008, acesso em janeiro de 2013.

9. WebCT - disponível em http://webct.uga.edu , acesso em janeiro de 2013.
10. Moodle - disponível em www.moodle.org.br,acesso em agosto de 2010.

11. CoL - disponível em http://col.redealuno.usp.br, acesso em janeiro de 2013.

12. TelEduc - disponível em www.teleduc.org.br, acesso em janeiro de 2013.

13. dotLRN - disponível em www.dotlrn.org, acesso em janeiro de 2013.

14. Blackboard - disponível em www.blackboard.com, acesso em janeiro de 2013.

15. eProinfo - disponível em www.eproinfo.mec.gov.br, acesso em janeiro de 2013.

16. Dokeos - disponível em www.dokeos.com, acesso em janeiro de 2013.

17. Kenski V. Tecnologias e Ensino Presencial e a Distância. Ed: Papirus, 2005.

18. Netiquetas - disponível em http://pt.wikipedia.org/wiki/Netiqueta, acesso em janeiro de 2013

19. Telles M. Boletim Eletrônico Tecnologia Aplicada à Educação ano III, número 11 - 27 de agosto de 2010, disponível em www.dynamiclab.com, acesso em agosto de 2010.

20. Photoshop CS5 - disponível em www.adobe.com/br, acesso em janeiro de 2013.

21. Robô japonesa vira cobaia de estudantes de Odontologia - disponível em http://www1.folha.uol.com.br/folha/inf ormatica/ult124u712357.shtml, acesso em janeiro de 2013.

22. Sílvio Meira, Eng ${ }^{\circ}$ Eletrônico; PhD em Computação - 25/02/2010 
23. Cresce o abismo tecnológico entre gerações - Tom Brady - Folha de São Paulo, 17/05/2010

24. Levy P. Cibercultura. São Paulo: Editora 34, 1999.

25. Teleodontologia amplia possibilidades para especialistas e pacientes. RevAssoc Paul Cir Dent;66(2):86-92, 2012.
ABSTRACT
In the era of collaboration, arises Distance Education (DE) as a powerful tool for the dissemination of realities, allowing the im- portance of $\mathrm{BDH}$ is disclosed properly.

Several initiatives are being taken in an articulate manner in order to facilitate the creation and consolidation of a network of collaborative working in Telehealth and Teledentistry for the dissemination and implementation of Banks Human Teeth at your college or research center based on the path followed by School of Dentistry, USP.

Descriptors: Telehealth, Teledentistry, Distance Learning, Social Networks, Teeth Bank. 